\title{
Peroxidase Isozyme Profiles in Compatible and Incompatible Pear-Quince Graft Combinations
}

\author{
Hatice Gulen ${ }^{1}$ \\ Department of Horticulture, Uludag University, Bursa, Turkey \\ Rajeev Arora ${ }^{2}$ \\ Department of Horticulture, Iowa State University, Ames, IA 50011-1100
}

Ali Kuden

Department of Horticulture, University of Cukurova, 01330 Adana, Turkey

Stephen L. Krebs

David G. Leach Research Station of Holden Arboretum, 1890 Hubbard Rd. Madison, OH 44057

\begin{abstract}
Joseph Postman
U.S.Department of Agriculture, Agricultural Research Service, National Clonal Germplasm Repository, Corvallis, OR 97333
\end{abstract}

\begin{abstract}
AdDitional INDEX words. Cydonia oblonga, grafting, incompatibility, Pyrus communis
Abstract. The similarity or differences of peroxidase isozymes in rootstocks and scions may influence their graft compatibility. This study was conducted to identify peroxidase isozymes that may be used as markers to predict compatibility between pear (Pyrus communis L.) and various quince (Cydonia oblonga Mill.) clones. 'Bartlett' (BT) and 'Beurre Hardy' $(\mathrm{BH})$ pear cultivars are known to form incompatible and compatible grafts, respectively, with quince rootstocks. The two pear scion cultivars were budded on 'quince A' (QA), 'quince BA-29', and 15 selected quince clones from Turkey. Bark and cambial tissues were taken from nonbudded rootstocks and scions, and $4 \mathrm{~cm}$ above and below the graft union for peroxidase isozyme analysis performed by starch gel electrophoresis. Isoperoxidase analyses were also performed on samples from the graft unions collected 12 months after grafting. Many isozyme bands were observed commonly in the two scions; however, one anodal peroxidase A was detected in BH (compatible scion) but not in BT (incompatible scion) samples. This isoperoxidase was also detected in QA, Quince BA-29, and nine of the Turkish quince clones. Another isoperoxidase, band B, was detected in BH but not in BT or any of the rootstocks. However, the compatible (BH/QA) and moderately compatible (BT/BA-29) graft union tissues contained bands A and B whereas incompatible graft union tissues (BT/QA) lacked both. Graft union samples involving BT and five Turkish quince clones (705, 609-2, $\mathbf{7 0 2 , 8 0 4}$, and 806) had both ' $A$ ' and ' $B$ ' isoperoxidases while one or both of these bands were absent in nonbudded graft partners. Field observations of 3.5 year-old grafts of BT and Turkish quince clones revealed that the vegetative growth (vigor) of BT scion was significantly greater, when grafted on these five clones, than that in graft combinations with other clones. We suggest that matching of isoperoxidase ' $A$ ' in quince rootstocks and $B H$ pear scion may be associated with a compatible graft combination. Additionally, presence of isoperoxidases ' $A$ ' and ' $B$ ' in the graft union tissues may be used as an indicator to predict a compatible graft between $\mathrm{BT}$ and quince rootstocks.
\end{abstract}

Graft incompatibility occurs due to anatomical, physiological, and genetic reasons (Hartmann et al., 1997). Moore (1983) suggested that graft incompatibility may be caused by lack of vascular redifferentiation and regeneration of phloem, or by cellular necrosis at the graft interface. These abnormalities result from anatomical mismatching between scion and rootstock (Yeoman, 1978), lack of lignification of cells interlocked at the graft union (Hartmann et al., 1997), and the detrimental effects of unknown chemical or physiological signals across the graft interface (Gur et al., 1968). The earliest methods used to detect graft incompatibility relied on the external symptoms such as graft union malformations, yellowing of foliage, decline in veg-

Received for publication 2 Sept. 2001. Accepted for publication 29 Oct. 2001. Journal paper J-19612 of the Iowa Agriculture and Home Economics Experiment Station, Ames, project 3601, and supported by Hatch Act and State of Iowa funds. We are grateful for financial support from the Scientific and Technical Research Council of Turkey (TUBITAK)-NATO Fellowship awarded to Hatice Gulen to conduct this research in Rajeev Arora's laboratory, Research Fund of Cukurova University-Turkey, and West Virginia University Agricultural and Forestry Experiment Station.

${ }^{1}$ Former graduate student. Currently postdoctoral research associate.

${ }^{2}$ Associate professor and corresponding author; e-mail rarora@iastate.edu. etative growth and vigor, marked differences in growth rate of scion and rootstock (Hartman et al., 1997), or anatomical abnormalities after grafting. This method requires waiting until the symptoms are visible, which could take years. Additionally, early anatomical observations may not always correlate with long-term graft survival (Andrews and Marguez, 1993).

Santamour et al. (1986) reported that isozyme analysis of scions and rootstocks could be used to predict incompatibility before grafting in different cultivars of Chinese chestnut (Castanea mollisima Blume). When peroxidase isozyme phenotypes of stock and scion matched, grafting resulted in a compatible union and the restoration of vascular continuity. In contrast, if isozyme phenotypes of graft partners were different, callus formation was impaired at the graft union (Santamour, 1988b). Similar results were obtained for intraspecific grafts of red oak (Quercus rubra L.) (Santamour, 1988c).

Compared to intraspecific grafts, where formation of a compatible union is fairly common, interspecific and intergeneric grafting are relatively uncommon and unsuccessful (Hartmann et al., 1997). However, some exceptions exist. For example, quince (Cydonia oblonga), particularly clones 'QA', 'QC', and 'BA29', are common rootstocks for pear (Pyrus communis L.) in 
much of Europe (Lombard and Westwood, 1987). Aside from inducing precocious bearing, quince rootstocks also exert size control, causing a composite grafted pear tree to be reduced in size by $40 \%$ to $60 \%$ as compared to composites grafted on pear seedling rootstock and thereby making possible high-density orchards (Neri et al., 1989; Tesky and Shoemaker, 1978).

However, quince is graft-incompatible with a major pear cultivar, Bartlett (Hartmann et al., 1997), that is, therefore, typically grafted on quince by double-working, using a graftcompatible interstock 'Beurre Hardy' or 'Old Home'. This technique is relatively costly, and prone to pathological problems and lower grafting success (Baldini et al., 1977). Available quince clones and pear scions grafted on quince are also susceptible to iron-induced chlorosis, particularly in calcareous soils that are found typically in Mediterranean countries, including parts of Turkey (Kacar, 1994). Hence, there is a need to develop new selections of quince that are compatible with major pear cultivars such as 'Bartlett', and are also tolerant to calcareous soils. Ongoing research at University of Cukurova in Turkey has identified 15 promising quince clones in the southeast part of Turkey which possess increased tolerance to calcareous soils (Kuden and Torun, 1998). However, their graft compatibility with the 'Bartlett' pear is unknown.

This research was initiated to survey the peroxidase isozyme profiles of quince A (QA) rootstock and two pear scions, 'Bartlett' (BT) and 'Beurre Hardy' (BH), which are known to form incompatible and compatible graft combinations, respectively, with 'QA'. The objective of this survey was to identify isozyme bands commonly present in the nonbudded QA rootstock and the compatible pear scion. Another objective of this study was to screen 15 selected quince clones, as mentioned previously, for the presence or absence of the isozyme bands that may be associated with compatibility or incompatibility, as identified in the previous objective. Additionally, samples from the 'graft unions' between various quince rootstocks and two pear scions were also analyzed for peroxidase isozymes to identify isozymes associated with compatible graft combinations.

\section{Materials and Methods}

Plant material. Seeds were collected from feral quince trees growing in southeast Turkey. The resulting seedlings were then planted at the Horticultural Research Station of Cukurova University, Adana, Turkey, and several clones of each seedling were propagated by stool bed layering. Based on the stem caliper (diameter measured at $15 \mathrm{~cm}$ above the soil level), the growth characteristics of 15 clones used in this study were classified to be semidwarf to very dwarf (Table 1). Specifically, very dwarf, dwarf, or semidwarf clones exhibited a caliper size equivalent to $\leq 70 \%, 71 \%$ to $80 \%$ or $81 \%$ to $90 \%$, respectively of that for QA. $\mathrm{BH}$ and BT, a compatible and incompatible pear scion, respectively, on QA rootstock (Tukey, 1978) were grafted onto 1-yearold rootstocks of QA. These pear scions were also grafted onto quince BA 29, a moderately compatible quince rootstock for BT (Lombard and Westwood, 1987) and onto 15 quince clones (Table 1) by chip budding. Triplicate samples (three different plants) of bark and cambial tissues were scraped from nonbudded rootstocks (1 year old) and scions (current year growth of $\approx 10$ year-old trees of BT and BH) using a razor blade; precaution was taken to completely exclude xylem tissues. Samples were also collected from the graft unions of budded plants at 12 months after grafting. Samples were frozen immediately in liquid $\mathrm{N}_{2}$ and stored at $-80{ }^{\circ} \mathrm{C}$ until used.

ISOPEROXIDASE PROFILES OF PEAR AND QUINCE BY STARCH GEL ELECTROPHORESIS (SGE). With a few modifications, the method of Santamour et al., (1986) was used for total protein extraction from samples. Roughly equal amounts of ground tissue $(\approx 0.06 \mathrm{~g})$ were placed in ceramic spot plate wells and crushed finely with glass rods in $0.6 \mathrm{~mL}$ of extraction buffer $(1 \mathrm{~mm}$ Tris-maleate, $5 \mathrm{~mm}$ sodium metabisulfite, $1 \%$ Tween 20 , and $4 \%$ polyvinylpyrroli-

Table 1. Summary of SGE profiles of isoperoxidases A and B (as shown in Figs. 1 and 2) for two pear scions (BT and BH), quince clones QA and BA-29, and 15 Turkish quince clones.

\begin{tabular}{|c|c|c|c|c|}
\hline Cultivar/clone & Growth characteristics & Nonbudded & Graft union w/BT & Graft union w/BH \\
\hline \multicolumn{5}{|l|}{ Scion } \\
\hline $\mathrm{BT}$ & & $---^{z}$ & ND & ND \\
\hline $\mathrm{BH}$ & & A, B & ND & ND \\
\hline \multicolumn{5}{|l|}{ Rootstock } \\
\hline QA & & A & --- & A, B \\
\hline BA-29 & & $\mathrm{A}$ & A, B & A, B \\
\hline 705 & Semidwarf & $\mathrm{A}$ & A, B & A, B \\
\hline $609-2$ & Semidwarf & --- & $\mathrm{A}, \mathrm{B}$ & A, B \\
\hline 707 & Dwarf & --- & $\mathrm{B}$ & A, B \\
\hline 702 & Very dwarf & A & A, B & A, B \\
\hline 608 & Very dwarf & A & A & A, B \\
\hline 601 & Semidwarf & --- & $\mathrm{B}$ & A, B \\
\hline 803 & Semidwarf & A & --- & A, B \\
\hline 804 & Semidwarf & A & A, B & A, B \\
\hline 806 & Semidwarf & $\mathrm{A}$ & A, B & A, B \\
\hline 117 & Dwarf & --- & --- & A, B \\
\hline 213 & Semidwarf & $\mathrm{A}$ & --- & A, B \\
\hline 606 & Semidwarf & A & --- & A, B \\
\hline 907 & Very dwarf & A & A & A, B \\
\hline 609 & Semidwarf & --- & --- & A, B \\
\hline 108 & Dwarf & --- & B & A, B \\
\hline
\end{tabular}

${ }^{{ }^{2}}$ Neither A nor B detected; ND = not done. 
done (PVP)-40; adjusted to $\mathrm{pH} 7.0$ before adding PVP). Filter paper wicks $(6 \mathrm{~mm}$ width $\times 10 \mathrm{~mm}$ length, Whatman no. 3$)$ were soaked in liquid extract, blotted semidry, and inserted in a slab gel of $11 \%$ potato starch (Connaught Labs, Inc., Swiftwater, Pa.). All extractions were carried out at $4{ }^{\circ} \mathrm{C}$.

Electrophoresis was performed at $4{ }^{\circ} \mathrm{C}$ using lithium-borate/ tris-citrate, $\mathrm{pH} 8.3$, buffer system (Wendel and Weeden,1989) at a constant voltage of $250 \mathrm{~V}$ until samples entered the gel and the bromphenol blue marker migrated $\approx 1 \mathrm{~cm}(\approx 30$ to $40 \mathrm{~min})$. Subsequently, paper wicks were removed, and the gels were run at $60 \mathrm{~mA}$ for $3.5 \mathrm{~h}$. Gels were then sliced and stained for peroxidase according to the method of Wendel and Weeden (1989). Gels were rinsed with distilled water after staining, and fixed and stored in $10 \%$ glycerol.The relative distance (Rf value) of the bands on the gel was calculated as described by Manganaris and Alston (1992) using $\mathrm{Rf}=1.0$, distance to the fastest band and $\mathrm{Rf}=0.0$, the starting point.

NATiVe POlyaCrylamide Gel Electrophoresis (PAGE) OF ACIDIC AND BASIC ISOPEROXIDASES. Although SGE provided data for acidic (anodal) isoperoxidases, basic (cathodal) isozyme profiles were not clearly resolved from these runs. Therefore, experiments were conducted to resolve acidic and basic isoperoxidases using native PAGE. Bark and cambial samples (collected as described above) were extracted according to the procedure of Krebs (1996), with slight modification. Ground tissues were homogenized in extraction buffer $(0.1 \mathrm{M}$ potassium phosphate $\mathrm{pH}$ 7.5, $30 \mathrm{~mm}$ boric acid, $50 \mathrm{~mm}$ L-ascorbic acid, 17 $\mathrm{mm}$ sodium metabisulfite, $16 \mathrm{~mm}$ dithiocarbamic acid, $1 \mathrm{~mm}$ EDTA, and 4\% (w/v) PVP-40; $0.1 \%(\mathrm{v} / \mathrm{v}) \beta$-mercaptoethanol was omitted and final $\mathrm{pH}$ was readjusted to 7.5 with $\mathrm{NaOH}$ ). Homogenates were centrifuged at $16,000 \mathrm{~g}_{\mathrm{n}}$ for $30 \mathrm{~min}$ at $4{ }^{\circ} \mathrm{C}$, and the supernatant was used for electrophoresis.

Discontinuous PAGE was performed with a PROTEAN II electrophoresis unit (Bio-Rad, Hercules, Calif) for acidic and basic proteins, respectively, according to Davis (1964) and Reisfeld et al., (1962). Five percent stacking gels and 10\% separating gels were prepared for both systems. Equal volumes of the sample (15 $\mu \mathrm{L})$ were loaded for each sample. Electrophoresis was performed at $10 \mathrm{~mA}$ for $20 \mathrm{~min}$, followed by $20 \mathrm{~mA}$ until the samples entered the separating gel (about $20 \mathrm{~min}$ ), and at $40 \mathrm{~mA}$ for $3 \mathrm{~h}$, thereafter. Gels were stained for peroxidase using the same procedure as described for SGE. The experiment was arranged in a randomized block design with three replications. Data were tested by analysis of variance, and mean separation was accomplished by least significant difference (LSD).

\section{Results}

All three extraction samples yielded identical profiles. Thus, data from a single representative experiment are presented herein.

Fig. 1. Starch gel electrophoresis of peroxidase isozymes of two pear scions and 17 quince rootstocks (19 lanes total). Lanes: $1=\mathrm{BH}, 2=\mathrm{BT}, 3=\mathrm{QA}, 4=\mathrm{BA}-29$, and lanes 5-19=quince clones 705, 609-2, 707, 702, 608, $601,803,804,806,117,213,606,907,609$, and 108, respectively. Isoperoxidase profiles were divided into Zones I, II, and III. A = the isozyme band $(\mathrm{Rf}=0.88)$ that is common in $\mathrm{BH}$ scion, $\mathrm{QA}$, and some of the quince clones. $\mathrm{B}=$ the isozyme band $(\mathrm{Rf}=0.68)$ that is unique to $\mathrm{BH}$.
ISOPEROXIDASE PROFILES OF PEAR AND QUINCE BY SGE. SGE profiles of isoperoxidases of nonbudded scion and rootstock revealed predominantly anodal isoperoxidases, whereas cathodal isoperoxidases could not be observed by this technique (Fig. 1). For ease of visualization, isozyme profiles were divided into three zones of activity, ZI,Z II and Z III. The data indicated that although some common bands were present in the scion and rootstocks in the $\mathrm{Z}$ I profiles, all the Z II and Z III isoperoxidases were present only in the scion or in the rootstocks, respectively. Analysis of Z I profiles revealed an isoperoxidase band (band $\mathrm{A} ; \mathrm{Rf}=0.88$ ) that was present in $\mathrm{BH}$ (a compatible pear scion), absent in BT (an incompatible pear scion), and present in 'QA', 'Quince BA-29', and nine of the Turkish quince clones. Another noteworthy isoperoxidase band (band $\mathrm{B} ; \mathrm{Rf}=0.68$ ) was observed in $\mathrm{BH}$ scion, but not in BT or in any of the rootstocks. Consequently, band $\mathrm{A}$ was the common band in $\mathrm{BH}$ scion and most of the rootstocks, band $\mathrm{B}$ was unique only to $\mathrm{BH}$, and $\mathrm{BT}$ lacked both bands $\mathrm{A}$ and $\mathrm{B}$.

Isoperoxidase patterns of the graft union samples, taken 12 months after grafting are shown in Fig. 2. Preliminary experiments indicated identical isozyme profiles across all graft unions involving $\mathrm{BH}$ scion and quince rootstocks (data not presented). However, differences were observed among graft unions involving BT and quince rootstocks. Therefore, data for only the BH/ QA graft union is presented herein along with all the graft combinations involving BT (Fig. 2). In general, the isoperoxidase bands observed in the graft union samples, particularly in Z I, were darker than those in nonbudded graft partners (compare Figs. 1 and 2). Comparison of compatible (BH/QA), moderately compatible (BT/BA-29), and incompatible (BT/QA) graft combinations indicated that more isoperoxidase bands were present in compatible and moderately compatible graft union samples than in the incompatible combination.

Isozyme profiles shown in Fig. 2 indicate that the graft union phenotype is additive, i.e., the sum of both scion and rootstock banding patterns as shown in Fig. 1. However, a few exceptions to this observation, particularly with regards to isozyme bands A and B, were noted. For the sake of simplification, data from Fig. 1 and 2 were summarized and presented in Table 1. Information gleaned from Table 1 indicates that isoperoxidases A and B were not present in some graft union samples even though they were 


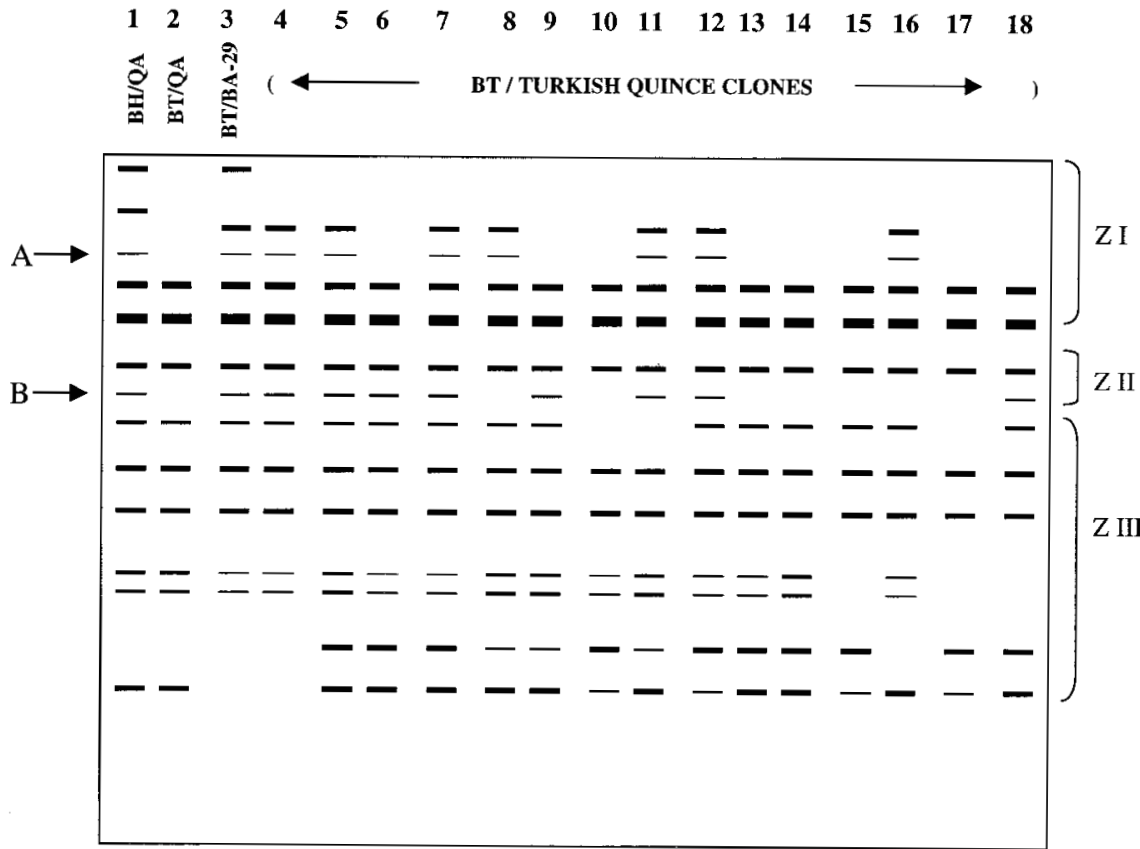

clones, no association could be observed between peroxidase activity and growth characteristics of the rootstock.

\section{Discussion}

SGE PROFILES OF PEROXIDASE ISOZYMES FROM NONBUDDED PEAR SCIONS, QUINCE ROOTSTOCKS, AND THEIR GRAFT UNIONS. Past research with other genera showed that peroxidase isozyme analysis of rootstock and scion before grafting could be used to predict intraspecific compatibility or incompatibility. Evidence to support this notion, although correlative in nature, comes from studies with intraspecific grafts of Chinese chestnut, red maple (Acer rubrum L.) and red oak (Quercus rubra L.) (Santamour, 1988a, 1988b, 1988c, 1989; Santamour et al., 1986). Results from these studies showed the presence of matching isoperoxidase phenotypes of rootstock and scion as correlated with compatible graft unions between clones or cultivars within a

Fig. 2. Starch gel electrophoresis of peroxidase isozymes of graft union samples (12 month after grafting) of all the combinations representing BT/quince and BH/QA (18 lanes total). Lanes: $1=\mathrm{BH} / \mathrm{QA}, 2=\mathrm{BT} / \mathrm{QA}, 3=\mathrm{BT} / \mathrm{BA}-29$, and lanes 4-18 = BT/quince clones 705, 609-2, 707, 702, 608, 601, 803, 804, 806, $117,213,606,907,609$, and 108, respectively. Zones I, II, and III, and bands A and $\mathrm{B}$ are as in Fig. 1 .

present in nonbudded individual graft partners. Conversely, these isozymes were present in some graft union samples despite their absence in one or both graft partners. For example, all graft union samples involving $\mathrm{BH}$ and quince rootstocks contained both bands A and B, whereas BT/QA union samples had neither band A nor B, even though nonbudded QA samples contained band A (Table 1). Also, BT/BA-29 (a moderately compatible graft) and eight graft combinations of BT/quince clones (705, 609-2, 707, $601,108,702,804$, and 806) contained band B, even though it was absent in nonbudded graft partners; four of the latter eight and BT/ BA-29 also contained both A and B (Table 1). Furthermore, BT/ quince clone (609-2) contained both bands A and B in spite of their absence in either graft partner.

Isozyme profiles of samples also taken from $4 \mathrm{~cm}$ above or below the graft union at $1,2,3$, and 12 months after budding were identical to those of nonbudded rootstock samples, and therefore, are not presented.

NATIVE PAGE OF ACIDIC AND BASIC ISOPEROXIDASES. Native PAGE of peroxidase was performed to obtain additional information for both acidic and basic isozymes in nonunion samples of the two pear scions (BT and BH), QA, BA-29 and the 15 Turkish quince clones. Native PAGE of acidic peroxidases showed a pattern similar to that of anodal peroxidases on SGE (data not presented). However, better isozyme separation and sharper bands were obtained in the native PAGE of basic peroxidase (Fig. 3) compared to that in the cathodal part of SGE, which only had few faint bands. Only one band with, $\mathrm{Rf}=0.91$, was observed commonly in BH scion and all of the rootstocks whereas BT did not contain this band. Moreover, BT did not contain basic peroxidases. Although, different isoperoxidase profiles were observed among the quince

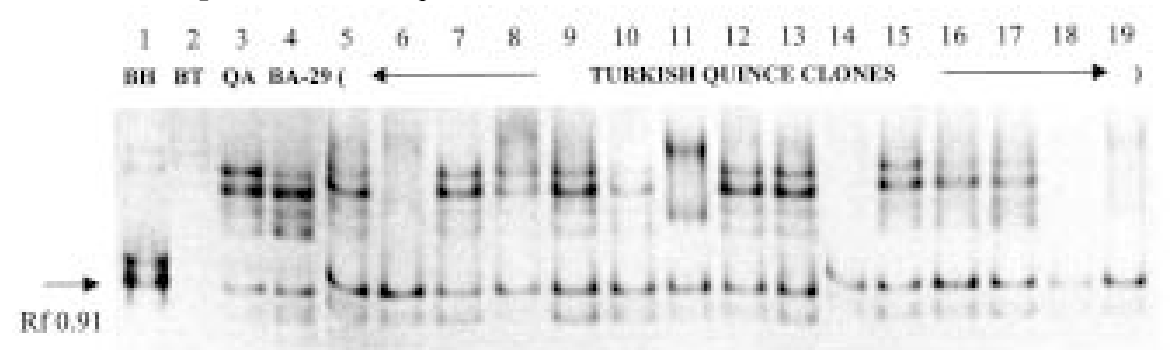
species. On the other hand, incompatible graft partners of these species lacked similarity of isozyme profiles.

Results from the present study support Santamour and coworkers' notion and extend it to intergeneric grafts. Although only one compatible or incompatible graft combination was used in this study, our data suggest that a specific isoperoxidase (band $\mathrm{A} ; \mathrm{Rf}=0.88$ ) might be associated with compatibility of Pyrus communis/Cydonia oblonga. It was the only band observed in both QA and BH (a compatible scion) but was absent in BT (an incompatible scion) (Fig. 1). Moreover, none of the BT isoperoxidases matched the isozymes in QA.

The specific role of peroxidases in graft compatibility/incompatibility is not clearly understood. However, based on the well established role of peroxidase in cell wall lignin biosynthesis, it has been suggested (Santamour, 1988b) that dissimilarities in isoperoxidase composition between stock and scion might result in abnormal lignification and lack of vascular connections at the graft union, resulting in an incompatible combination. How this specific isoperoxidase (identified as band $\mathrm{A}$ in the present study) is different from other isozymes and what role it might play in graft compatibility remains unclear. It is well established, however, that different isoperoxidases are involved in production of structurally different lignins which perhaps have different bonding (with cell wall carbohydrates) characteristics (Santamour, 1988c).

Fig. 3. Native PAGE of basic (cathodic) peroxidases from nonunion (nonbudded) samples of two pear scions and 17 quince rootstocks (19 lanes total). Samples: $1=\mathrm{BH}, 2=\mathrm{BT}, 3=\mathrm{QA}, 4=\mathrm{BA}-29$, and lanes 5-19= quince clones 705, 609$2,707,702,608,601,803,804,806,117,213,606,907,609$, and 108 , respectively. The isozyme band $(\mathrm{Rf}=0.91)$ is common in $\mathrm{BH}$ scion, $\mathrm{QA}$, and respectively. The isozy
all of the quince clones. 
Table 2. Current year shoot growth (mean $\pm \mathrm{SE}$ ) of two pear scions $(\mathrm{BH}$ and BT) grafted on 15 Turkish quince clones. Three shoots per graft and three separate grafts per quince clone were analyzed for shoot growth.

\begin{tabular}{lccl}
\hline \hline $\begin{array}{l}\text { Clone } \\
\text { no. }\end{array}$ & $\begin{array}{c}\text { Grafted w/BH } \\
(\mathrm{cm})\end{array}$ & $\begin{array}{c}\text { Grafted w/BT } \\
(\mathrm{cm})\end{array}$ & LSD $^{\text {( }}$ \\
\hline 705 & $100.0 \pm 1.2$ & $98.2 \pm 0.9$ & $4.0^{\text {NS }}$ \\
$609-2$ & $107.3 \pm 1.5$ & $101.00 \pm 2.1$ & $7.0^{\text {NS }}$ \\
707 & $74.0 \pm 2.1$ & $52.7 \pm 1.2$ & $6.7^{*}$ \\
702 & $62.7 \pm 1.2$ & $57.7 \pm 1.5$ & $5.2^{\text {NS }}$ \\
608 & $68.3 \pm 0.9$ & $52.0 \pm 1.2$ & $3.2^{*}$ \\
601 & $98.3 \pm 1.8$ & $83.0 \pm 1.2$ & $5.9^{*}$ \\
803 & $101.7 \pm 3.2$ & $80.0 \pm 1.2$ & $9.4^{*}$ \\
804 & $100.3 \pm 1.7$ & $97.0 \pm 1.2$ & $5.9^{\text {NS }}$ \\
806 & $103.0 \pm 1.7$ & $98.0 \pm 1.5$ & $6.4^{\text {NS }}$ \\
117 & $70.0 \pm 1.2$ & $52.6 \pm 1.5$ & $5.2^{*}$ \\
213 & $108.6 \pm 2.0$ & $90.3 \pm 0.9$ & $6.1^{*}$ \\
606 & $114.6 \pm 2.9$ & $82.3 \pm 1.5$ & $9.0^{*}$ \\
907 & $56.6 \pm 0.9$ & $48.0 \pm 0.6$ & $2.9^{*}$ \\
609 & $120 . \pm 1.2$ & $95.6 \pm 2.3$ & $7.2^{*}$ \\
108 & $72.3 \pm 1.5$ & $56.0 \pm 1.2$ & $5.2^{*}$ \\
\hline
\end{tabular}

${ }^{\mathrm{z}}$ Mean separation between the two scion treatments was performed by LSD at $P<0.05$. Current year shoot growth of BH/QA (compatible combination) and BT/QA (incompatible combination) are $140.0 \pm 2.9$ and $66.3 \pm 1.9$, respectively (LSD value is $9.5^{*}$ ).

Ns, ${ }^{*}$ Nonsignificant and significant at $P<0.05$, respectively.

Our data also revealed a rather interesting scenario in which compatible graft union tissues contained isozyme bands A and B, one or both of which were absent in either or both graft partners. Conversely, incompatible graft union samples lacked bands A and $B$ even though they were present in one or both graft partners. For example, graft union tissues of BT/BA-29 (a moderately compatible combination) contained isoperoxidases $\mathrm{A}$ and $\mathrm{B}$ even though nonbudded BT lacked both bands and BA-29 contained only band A (Table 1). On the other hand, samples from BT/QA graft union (an incompatible combination) lacked isozymes $\mathrm{A}$ and $\mathrm{B}$ in spite of the presence of isozyme A in QA. These observations taken together with the presence of isozymes A and B in BH/QA and BH/BA-29 graft union samples (both compatible combinations) suggest that activity of $\mathrm{A}$ and $\mathrm{B}$ isoperoxidases may be associated with graft compatibility between pear and quince. Based on this hypothesis and the data presented in Table 1 and Fig. 2 , it can be argued that five of the fifteen quince clones $(705,702$, $804,609-2,806$ ) used in this study might form compatible graft unions with BT. Field observations on the vigor (measured as the vegetative growth of current year shoots) of 3.5 year-old grafts of the 15 quince clones with $\mathrm{BT}$ and $\mathrm{BH}$ scions support this notion (Table 2). The data indicated that $B T$ scions exhibited significantly higher vigor when grafted with the above-mentioned five Turkish clones compared to the rest of clones, which was evidenced by a statistically similar vegetative growth of $\mathrm{BT}$ and $\mathrm{BH}$ on these five quince clones. Grafts of these scions with the other ten Turkish quince clones resulted in significantly lower vegetative growth of BT scions compared to that of $\mathrm{BH}$. Moreover, the mean vegetative growth of BT scions grafted on these five quince clones was at least $30 \%$ greater than that of BT when grafted on standard QA, a combination known to be incompatible. Since graft failure (incompatibility) can occur even several years after the initial graft, we will continue to monitor the performance of BT scions on these five Turkish clones.

Rather interesting patterns of appearance or disappearance of isoperoxidases A and B (as discussed above) may be brought about due to altered gene expression (de novo expression or suppression). These changes may be triggered by a signal produced by the contact (between the two graft partners). Pirovana et al. (2000) recently identified, using an in vitro model system comprised of cell cultures from compatible and incompatible pear and quince combinations, 60 putative genes that are expressed differentially in compatible and incompatible combinations. One of these genes was shown to have a strong homology with a gene encoding pathogenesis-related (PR) protein.

Appearance of new or disappearance of previously observed peroxidases may also be associated with the defense response of plant against pathogens (Stahmann and Demorest, 1973). These authors reported a rapid increase in peroxidase activity and appearance or disappearance of some peroxidase isozymes when plants were inoculated with selected viruses, bacteria, or fungi. This change may be explained by altered lignin biosynthesis upon pathogen attack whereby new lignin formation (involving certain peroxidases) could prevent pathogen penetration. In our study, peroxidase isozymes A and $\mathrm{B}$ could be responsible for compatible graft unions through their role in lignin biosynthesis, resulting in a stronger graft union.

Some reports have attempted to associate the intensity (a measure of relative activity) of certain isozyme bands in graft union samples with compatibility or incompatibility. For example, Copes (1978) reported much darker staining of certain isoperoxidases from tissues of incompatible unions than that of the same bands from tissues of compatible unions or from nonunion areas. We, too, observed different staining intensity between graft union and nonunion samples. However, graft union samples of both compatible (BH/QA) and incompatible (BT/QA) combinations showed darker bands, particularly in Z I profiles, than samples from nonunion areas (compare Figs. 1 and 2). This observation suggests that peroxidase activity may be increased by wounding, a conclusion also reached by Macheix et al., (1986). Our data also indicated the presence of more isoperoxidase bands in compatible (BH/QA) and moderately compatible (BT/BA-29) graft union samples than those in incompatible graft union (BT/QA) (Fig. 2). These isozymes may be associated with compatible unions via their role in lignin biosynthesis and/or modulating auxin content, regardless whether in connection with differentiation of xylem and phloem or with defense against pathogen invasions.

NaTIVE PAGE OF ACIDIC AND BASIC ISOPEROXIDASES. Many basic isoperoxidases were visualized, but no correlation was found between basic isoperoxidase activity (Fig. 3) and growth characteristics of rootstocks (Table 1). It is generally believed that each group of peroxidases has a specific role in plant metabolism. Anodic (acidic) peroxidases are wall-associated and exhibit a high affinity for cinnamyl alcohols in vitro, whereas function of cathodic (basic) isozymes is unclear. It has been suggested, however, that they might provide $\mathrm{H}_{2} \mathrm{O}_{2}$ for other peroxidases (Walter, 1992). Although, lignification and growth and development are associated with acidic and basic peroxidases, respectively (Gaspar et al., 1982), recent evidence has correlated activity of four basic isoperoxidases to lignin deposition in castor bean (Ricinus communis L.) (Bruce and West, 1989). In the present study, one basic peroxidase band $(\mathrm{Rf}=0.91)$ was observed commonly in all of the rootstocks and $\mathrm{BH}$ (a compatible scion), and, therefore, might be associated with lignification and graft compatibility in pear/quince graft combination. Interestingly, however no basic peroxidases were detected in BT. The reason for this apparent anomaly is not clear. 


\section{Conclusions}

Our data indicate that electrophoretic detection of compatibility or incompatibility using isoperoxidase analysis could be used in pear/quince (intergeneric) graft combinations. Results from the isoperoxidase analyses coupled with the field observations of our 3.5 year-old experimental plants suggest that five Turkish quince clones namely, 705, 609-2, 702, 804, and 806 may be compatible with BT scion. Prediction of graft compatibilityincompatibility using isoperoxidase pattern of the union can be useful in early rootstock selection. This biochemical analysis would eliminate the need to wait for appearance of symptoms of anatomical abnormalities, which may take years.

\section{Literature Cited}

Andrews, P.K. and C.S. Marquez. 1993. Graft incompatibility, p. 183 231. In: J. Janick (ed.). Horticultural reviews. vol. 15. Wiley, New York.

Baldini, E., G. Costa, and S. Sansavini. 1977. A twelve year survey on various interstocks for 'Beurre Bos'c, 'Beurre Anjou', 'Clapps Favourit'e and 'William' pear trees on quince. Acta Hort. 69:105-113.

Bruce, R.J. and C.A. West. 1989. Elicitation of lignin biosynthesis and isoperoxidase activity by pectic fragments in suspension cultures of castor bean. Plant Physiol. 91:889-897.

Copes, D.L. 1978. Isozyme activities differ in compatible and incompatible Douglas-fir graft unions. For. Sci. 24:297-303.

Davis, B.J. 1964. Disc electrophoresis, method and application to human serum proteins. Ann. N.Y. Acad. Sci. 121:404-427.

Gaspar, T.H., C.L. Penel, T. Thorpe, and H. Grappin, 1982. Chemistry and biochemistry of peroxidases, p. 10-60. In:T.H. Gaspar, C.L.Penel, T. Thorpe, and H. Grappin (eds.). Peroxidases (1970-1980): A survey of their biochemical and physiological roles in higher plants. Univ. Geneva, Geneva, Switzerland.

Gur, A., R.M. Samish, and E. Lifshitz. 1968. The role of the cyanogenic glycoside of the quince in the incompatibility between pear cultivars and quince rootstocks. Hort. Res. 8:113-134.

Hartmann, H.T., D.E. Kester, F.T. Davies, Jr., and R.L. Geneve. 1997. Plant propagation: Principles and practices. Prentice-Hall, Upper Saddle River, N.J.

Kacar, B. 1994. Soil analysis. Ankara Univ. Press, Ankara, Turkey.

Krebs, S.L. 1996. Normal segregation of allozyme markers in complex rhododendron hybrids. J. Hered. 87:131-135.

Kuden, A. and I. Torun. 1998. Investigations on the compatibility of selected quince clones with pear varieties. Abstr. XXV Intl. Hort. Congr. Brussels, Belgium, 2-7 Aug. p. 459.

Lombard, P.B. and M.N. Westwood. 1987. Pear rootstocks, p. 145-184. In: R.C. Rom and R.F. Carlson (eds.). Rootstocks for fruit crops. Wiley, New York.
Macheix, J.J., A. Fleuriet, and M.P. Quessada. 1986. Involvement of phenols and peroxidases in wound healing and grafting, p. 267-286. In: H. Grappin, C.L. Penel, and T.H. Gaspar (eds.). Molecular and physiological aspects of plant peroxidases, Univ. of Geneva, Geneva, Switzerland.

Manganaris, A.G. and F.H. Alston. 1992. Inheritance and linkage relationships of peroxidase isoenzymes in apple. Theor. Appl. Genet. 83:392-399.

Moore, R. 1983. Physiological aspects of graft formation, p. 89-105. In: R. Moore, (ed.). Vegetative compatibility responses in plants, Baylor Univ. Press, Waco, Texas.

Neri, D., S. Sansavini, and M. Capobianco. 1989. Performance of micropropagated and budded pear trees: Interaction between scion and dwarf quince clones. Acta Hort. 256:69-76.

Pirovana, L., G.A. Sacchi, A. Abruzzese, S. Musacchi, G. Bernardi, S. Sansavini, and M. Cocucci. 2000. Study of gene expression in compatible and incompatible pear/pear and pear/quince grafts by mRNA differential display: Abstr. VIII Intl. Symp. Pear, Univ. of Bologna, Bologna, Italy, 4-9 Sept. p. 109-110.

Reisfeld, R.A., U.J. Lewis, and D.E. Williams. 1962. Disk electrophoresis of basic proteins and peptides on polyacrylamide gels. Nature 195:281-283.

Santamour, Jr., F.S. 1988a. Graft compatibility in woody plants: A expanded perspective. J. Environ. Hort. 6:27-32.

Santamour, Jr., F.S. 1988b. Graft incompatibility related to cambial peroxidase isozymes in chinese chestnut. J. Environ. Hort. 6:33-39.

Santamour, Jr., F.S. 1988c. Cambial peroxidase enzymes related to graft incompatibility in red oak. J. Environ. Hort. 6:87-93.

Santamour, Jr., F.S. 1989. Cambial peroxidase enzymes related to graft incompatibility in red maple. J. Environ. Hort. 7:8-18.

Santamour, Jr., F.S., A.J. McArdle, and R.A. Jaynes. 1986. Cambial isoperoxidase patterns in Castanea. J. Environ. Hort. 4:14-16.

Stahman, M.A. and D.M. Demores. 1973. Changes in isozymes of host and pathogen with special reference to peroxidase interaction, p. 405420 In: R. Byrde and C. Cutting (eds.). Fungal pathogenicity and the plant's response, Academic Press, New York.

Tesky, B.J.E. and J.S. Shoemaker. 1978. Tree fruit production. AVI Publ. Co., Inc., Westport, Conn.

Tukey, H.B. 1978. Dwarfing rootstocks for pear, p. 182-189. In: H.B. Tukey (ed.). Dwarfed fruit trees. Cornell Univ. Press, Ithaca, N.Y.

Walter, M.H. 1992. Regulation of lignification in defense, p. 329-352. In: T. Boller and F. Meins (eds.). Plant gene research: genes involved in plant defense, Springer-Verlag, New York.

Wendel, J.F. and N.F. Weeden. 1989. Visualization and interpretation of plant isozymes, p. 5-44. In: D.E. Soltis and P.S. Soltis (eds.). Isozymes in plant biology, Dioscordes Press, Portland, Ore.

Yeoman, M.M, D.C. Kilpatrick, M.B. Miedzybrodzka, and A.R. Gould. 1978. Cellular interactions during graft formation in plants: A recognition phenomenon? Symp. Soc. Expt. Biol. 32:139-160. 